\title{
Mood Psychopathologies: An Integrated Complexity-Based Interpretation
}

\author{
Massimo Cocchi1,2,3, Lucio Tonello1,3, Fabio Gabrielli1,3 \\ ${ }^{1}$ Paolo Sotgiu Institute for Quantitative \& Quantum Psychiatry \& Cardiology, L.U.de.S. University, Lugano, \\ Switzerland \\ ${ }^{2}$ Department of Veterinary Medical Sciences, University of Bologna, Bologna, Italy \\ ${ }^{3}$ Faculty of Human Sciences, L.U.de.S. University, Lugano, Switzerland \\ Email: massimo.cocchi@unibo.it
}

Received 13 January 2014; revised 11 February 2014; accepted 8 March 2014

Copyright (C) 2014 by authors and Scientific Research Publishing Inc.

This work is licensed under the Creative Commons Attribution International License (CC BY).

http://creativecommons.org/licenses/by/4.0/

(c) (i) Open Access

\begin{abstract}
If the mechanistic-reductionist cognitive approaches have been characterised by the metaphor of the "edifice", of the solid Cartesian rock, all the forms of knowledge founded on complexity theory have been characterised by the metaphor of the "network", of thinking in relationships, in a dynamic, fluid, open manner. In the field of mental illness, this means setting aside both the organicist paradigm and the pseudo-phenomenological, "sentimentalistic", and therefore ideological, paradigm, in order to have an integrated view of biological objectiveness and humanistic psychotherapy. That is to say, an expression of diverse interrelated contributions from the various disciplines (psychiatry, psychology, biochemistry, anthropology, quantum physics, mathematics, philosophy). The observer thus becomes a builder of models, a manager of complexity, giving treatment the character of a truly empathic relationship. This is all the more so where distressing pathologies are involved, such as Major Depression (MD) and Bipolar Disorder (BD), caput mortuum of psychiatry, because the absence of cogent biological markers seriously compromises every form of therapy. Hence the identification of a biological platform (fatty acids of platelets) as a starting point for a correct classification of MD with respect to $B D$.
\end{abstract}

\section{Keywords}

Complexity; Major Depression; Bipolar Disorder; Fatty Acids; SOM; Biology; Phenomenology

\section{Foreword}

Drawing on the contributions of Culloch, Paget, Von Foerster, Bateson, Maturana, Varela, Atlan, the epistemology of the Irremovable Method and Foundation has been thrown into crisis in favour of a systemic view, not 
characterised by linearity, where the observer is a builder of models, narrations to be shared in the hic et nunc, in the framework of the real world.

The observer is posed as an inter-worldly reality which operates through a plurality of cognitive strategies, within the epistemological-ecological, mind-world system, enabling an interpretation of reality that is neither ideological nor manipulatory.

Thus, from physical to biological systems, from mental processes to socio-economic structures, a gestaltic reorientation is needed in the name of complexity, beyond every interpretation that reduces the person to a mere expression of rules, practices, epistemic-Foucaultian discourses or to naïve spiritualistic emergences, the latter expressing the mere myth of the irreducibility of individual and collective behavioural dynamics to the properties of their elementary ingredients (a valid aid is provided by the general logical scheme of quantum state theory).

In extreme summary, complexity embodies a kind of self-organised, multifactoral knowledge, expressive of a plurality of models, open to unpredictability, to novelty, to the continuous intersection between observer and world in the construction of an open, mobile, non-dichotomic or foundationist weave.

So, as Bateson wrote prophetically, superseding the classic dichotomy between scientific culture and humanistic culture: "The beautiful and the ugly, the literal and the metaphoric, the sanity and madness, comical and serious... all these and even love and hate are matters that science presently avoids. But in a few years, when the split between problems of mind and problems of matter ceases to be a central determinant of what is impossible to think about, they will become accessible to formal thought” (G. Bateson \& M.C. Bateson 1987).

Edgar Morin, perhaps more than anyone else, has grasped with absolute clarity the theoretical and applicational nodes of complexity, the perverse drifts of official thought, of "blind intelligence": "In many contexts, then, the parcelled, compartmentalised, mechanistic, disjointed reductionist intelligence breaks up the problems, separates what is connected, and makes one-dimensional what is multidimensional. It is an intelligence at one and the same time short-sighted, long-sighted, colour-blind and one-eyed; in most cases it ends up by being blind. It destroys at birth the possibilities of comprehension and reflection, eliminating all possibilities of a correct judgement or a long-term view” (Morin, 2008).

In particular, Morin has tried, on the one hand, to trace man back to the Universe from whence he emerged; on the other, to capture him in his entirety (the entire, multi-coloured man, between reason and imagination, emotion and reflection): "The death knell sounds for an anthropology limited to a thin psycho-cultural band that hovers like a flying carpet over the natural universe" (Morin, 1973).

The new subject, expressing a process of which it is at the same time creator and created, indicating relationship, interaction, is homo sapiens-demens: rational, but also uncertain, unstable, confused, an unpredictable mixture of objective, logical, technical, empirical thought and subjective, phantasmal, mythical, magical thought.

Alongside, or behind, the Apollonian homo sapiens there emerges, overbearingly, "a being that smiles, laughs, cries, an anxious, anguished being... inebriated, ecstatic, violent, furious, inclined to love...".

In this way, from a rigorous phenomenology (Jaspers, 1963), not reduced to mere poetics of interior resonances, a serious phenomenology of the person is preserved: the being located in a "here and now", expressing its own irreducible position in which to pour forth depth, creativity, ever-new initiality (Husserl, 1911; Baker, 2000, 2002). Preserving the free creativity of the subject/person demands complexity as a circular, dialogical opening, where the negative, the Hegelian contradictions are not overcome (Aufhebung as abolition-conservation) with a view to absolute concretisation, but remain to indicate complementarity, without a privileged metapoint, a particular "epistemological sovereignty”, to use an expression of Morin's (Morin, 1984) and without remaining prisoners of the myth of the punctum inconcussum [irremovable foundation], with respect to which to establish a good judgement by homogenising them, on differences and contrapositions between various points of view. The important thing is to grasp how multiple points of view are produced reciprocally (against the hierarchisation of points of view, Magoroh Maruyama (1976) proposes the concepts of "demonopolisation" and "trans-spection"), that is to say the capacity to substitute and the asymmetry of the pluri-diversities of world views and entering into others' heads and, vice versa, without reducing the other's logic to one's own by an act of logical and dialectical domination.

In the treatment of psychopathologies, all this is translated into the reciprocal exchange and the mutual integration of phenomenological and biological approaches, in the intelligent dosing of biochemical and logotherapeutic dynamics, in the common sharing of the person as an autonomous, unique and irreducible expression. 


\section{Biological Roots and Phenomenological Emergence of Mental Illness}

It is undeniable that the depth of the ens sofferens, to be approached with a curative word (Laín Entralgo, 1970), cannot be traced only to disease-pathology or biomedical classification-but also to illness-experience of the malaise as lived-and sickness—the social determination of the condition (Young, 1982; Augé, 1984; Good, 1994).

For all societies, illness is an event to be interpreted; it is not just a biological fact but also a cultural one. Basically, illness is representation, interpretation, of a portion or of all reality by individuals in a certain social context. The medical description of the human body and the illness always refer back to culturally peculiar meanings.

In strict terms, we could say that the pain articulates its meanings in suffering, which is a restless reflection on the ineluctable, and nevertheless unexpected, occurrence of the illness.

It can be understood, then, that only medical practice that does not limit itself to the biomedical dimension, which is in any case an indisputable point of departure, but is able to meet with the suffering person in his or her intimacy, can ensure, if not salvation against the perverse myth of recovery, at least dignity of the treatment as a profound ethical and existential relationship.

Hence the opening towards intimacy as a dual construction of meaning, the planning of significances contributed to both by the patient, in trusting abandon, and by the physician, as a warm, experienced responsibility. The intimacy is inhabited by the treatment (sphere of essential meanings of living) and not by anxiety (sphere of intra-worldly commerces), precisely because the experience of illness is experience of a relational wound which destructures the biological and existential narration of the subject:

- Wounded in relation to his own body, in Der Zauberberg Thomas Mann says that "illness makes men more corporeal, it makes them all body" (1996) — from which, on the one hand, we wish to distance ourselves as it is a sign of the precariousness of existence, while on the other hand we want to master it as we never did when in good health, because the anguish of feeling expropriated by it, not only by the almost fleshly possibility of death, but also by its medical visibility (the anguish-increasingly flaunted, for that matter, and reiterated like a mantra - of the reification of the medical approach), makes us feel the full weight of our vulnerability;

- a relational wound with respect to everyday life, whose narrative laceration provokes at first dismay, then a steady eclipse towards an indeterminate space-time, which for this reason is anguishing and inhospitable, and requires an approach that is not simply clinical but, precisely, one of intimacy, which, as a profound expression of empathy, configures itself as discretion, the word held back, the gesture experienced, total attention for the suffering countenance in a mutual exchange of meanings.

In the case of mental illnesses, then, the social, cultural weight takes on an almost transcendent value, due to the often blurred correspondences between classification and natural object, between nosology and effective reality of the illness.

When all this is recognised, what remains, excluding the interpretations of meaning, is the structural necessity, when coping with the illness-in our case the psychopathology—of starting from the biological fact, from objective biological markers, without which experience, biographical narrations, cultural rootings would be empty just as biology, on the other hand, would be blind.

The meaning is not only the prerogative of philosophy, which certainly remains a strong interlocutor, but also of biology and biochemistry: the corporeal meaning/significance of a pathological event.

Certainly, a medicine limited to the biological fact cannot be extensive and ostensive of the illness. At the same time, however, no one should doubt-as however happens unfailingly—-that starting from a bio-medical platform can ipso facto reduce the physician to a pure functionary of the body and of the pathology connected with it.

Ultimately, we need to remind the alleged monolithic custodians of the thought of Husserl, Heidegger, Jaspers, Minkowski and Binswanger that rooting the pathology in biology does not mean expropriating the sick person of his illness and making the physician a mere functionary of the organism, an all-out pathologist who ignores biographies, experiences, corporeal dynamics and relational ontologies.

If anything, biographies, relationships, cultural expressions can be preserved in all their dignity, once their genuine biological matrix has been determined.

On the other hand, we risk only metaphysical hypostatisation and, therefore, a treatment rooted in an immo- 
bile metempirical "elsewhere".

A fruitful heuristic synthesis between Körper and Leib, erklären and verstehen (Husserl, 1977), as a true commitment to healing the "living flesh" (Fr. chair) (Merleau-Ponty, 1964), is possible only if we start from the biological roots of our being in the world (in der Welt sein).

Heidegger's figures of omnipotence (Allmacht) and impotence (Ohnmacht) (Binswanger, 1963), can be taken up and re-elaborated in a synthesis between the naturalistic, classificatory power of science and the ever-open possibility of phenomenology, avoiding the same Heidegger's anti-technicist derailments and the exacerbated revivals of Binswanger's phenomenology as a mere therapeutic praxis, without theoretical rigour.

Like psychiatry and psychology—bio-reductionist and limited to the illness—so too "antipsychiatry", which reduces the illness only to a social construction, process of control, of exclusion/inclusion managed by bio-power (Goffman, 1961; Foucault, 1965, 1994, 2004, 2008), unable to recognise the productivity/creativity of schizophrenic processes (Deleuze-Guattari, 2004), ends up by prejudicing the genuine dynamics of the treatment.

Hence the need for an objective biological reference able to act as a cogent platform in the treatment relationship, with reference to two distressing psychopathologies: MD and BD (Bowden, 2001).

\section{Biological Markers of Major Depression and Bipolar Disorder}

In the first experimental phase we selected two mathematical instruments, one complex (Self-Organizing MapSOM) and the other simple (the B2 index). These were to show their validity subsequently not only in defining the pathology of Major Depression and the Bipolar Disorder, but also for drawing plausible deductions as regards the biological value of the two molecular mood disturbances.

The SOM is an artificial neural network able to put together similar objects and separate them from very different objects according to their characteristics.

The B2 index [so called by the authors of the research (Cocchi and Tonello)] is derived from a mathematical operation that considers the characteristics of the molecular weight and melting point of the fatty acids isolated and recognised by the SOM, in order to distinguish between the two disorders.

Proceeding by stages we can say that the two groups of patients examined in the first phase of the research (apparently normal and depressed) were determined by the fatty acids of the platelets. This cell type was chosen for its morphological and functional peculiarities, i.e. the presence of receptors for neuro-transmitters, in particular serotonin, and for other characteristics that make them similar to neurons.

The results obtained experimentally, interpreted by a non-linear mathematical function, the SOM, and by a linear mathematical function, the B2 index, made it possible to distinguish "psychiatric" patients from "normal" patients.

The problem resided in the fact that the psychiatric diagnosis generally made was of Major Depression, while the arrangement of the subjects in the picture traced by the SOM and the B2 index made us feel that some aspects of the diagnosis were not entirely clear.

The arrangement of the cases on the SOM and the evaluation of the B2 index (negative or positive) led us to seek an opportunity to relaunch the experiment, which would be able to distinguish apparently normal subjects from those affected by Major Depression and Bipolar Disorder.

The opportunity arose with funding from the Marche Region in Italy and, in two years of intense work in collaboration with psychiatrists, biochemists, molecular biologists, mathematicians, quantum physicists and philosophers, the much sought-after result was obtained, confirming that our intuition was correct: the depressed subjects were isolated from the bipolar ones, beyond any interpretative, classificatory and psychiatric discussion.

With these results in our hands we began to reflect on the distribution and logic of the numbers that had been closely correlated with psychiatric illnesses, because they did not take into consideration the therapies conducted or anything which could be connected with the patients from the outside.

All this led us to suppose that there was something already written in the platelets able to simulate the condition of the neuron, at least as far as serotonin level was concerned. Consistently with this observation we wrote some papers concerning the molecular uniqueness of Major Depression, the role of membrane viscosity and the molecular reflections on the state of consciousness and the mechanical strength of the membrane.

This work will perhaps be reviewed when it is possible to carry out molecular mapping of the neuron, as agreed on the occasion of the Palermo Conference. 
In the second stage of experimentation, research was then carried out using a combination of biology and non-linear mathematics to establish, in the psychiatric area of mood disorders, whether it was possible in the platelets, especially in their fatty acids, to identify molecular characteristics able to provide a clear, precise classification of subjects with Major Depression (MD) and Bipolar Disorder (BD). The results obtained once again confirmed the original data, using an artificial Neural Network, in particular a network known as a Self-Organizing Map (SOM) (Cocchi et al., 2008; Cocchi \& Tonello, 2010). The SOM is a network algorithm of unsupervised competitive learning, devised by Teuvo Kohonen in 1981-1982 (Kohonen, 1982, 1998, 2001).

Thanks to the above combination, using platelet fatty acids (Palmitic, Linoleic and Arachidonic), the SOM and the mathematical index B2 (obtained by adding together the percentages of each fatty acid multiplied by their respective melting points and divided by their molecular weights) we were able to distinguish MD from $\mathrm{BD}$ for the first time ever. Thus we obtained the evaluation of an indirect expression of membrane viscosity, which led us to correlate with the membrane viscosity of the neuron thanks to the correlation shown between the passage of the arachidonic acid from the platelets to the brain (Cocchi, Tonello, \& Gabrielli, 2012). The B2 index is negative in $\mathrm{MD}$ and positive in $\mathrm{BD}$. This result leads to the observation that the membranes in $\mathrm{MD}$ are considerably less viscous than those of normal, BD and psychotic patients. Thus it can be said that subjects with MD have certain specific and exclusive molecular characteristics (Cocchi, Tonello, \& Gabrielli, 2012b). On this basis we were able to explain the quantitative biomolecular approach used for Major Depression and hypothesise that in mood disorders there is a quantitative path, going from the viscosity of the cell membrane and passing through the Gs $\alpha$ protein and Tubulina (Cocchi et al., 2010b). Figures 1-8 summarise the principal steps of the research.

Because it is not possible to manipulate the SOM, differently from the statistical evaluation, the SOM and the B2 index result (Figures 4, 5) show that patients with Major Depression belong to a quite separate area from that of healthy and bipolar subjects. By observing the arrangement of the data on the SOM, we also see a region (high-left corner, Figure 1) which we attribute to psychotic subjects on a diagnostic basis.

We interpreted these events in terms of breakage of symmetry (Cocchi et al., 2012c), which confirms the fact that MD is an illness that stands quite apart from the normal, bipolar and psychotic conditions (Figure 9).

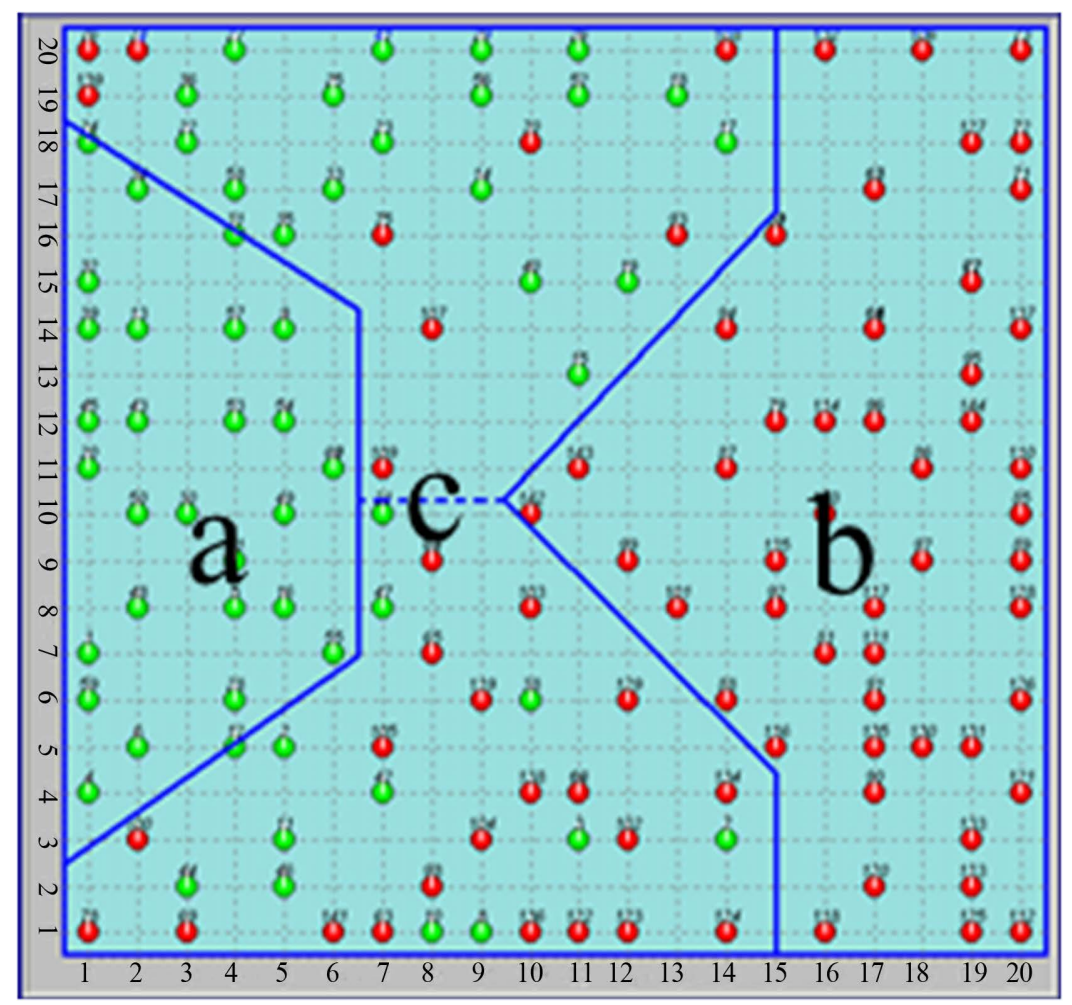

Figure 1. Distribution of all cases of the first experiment (first SOM). 


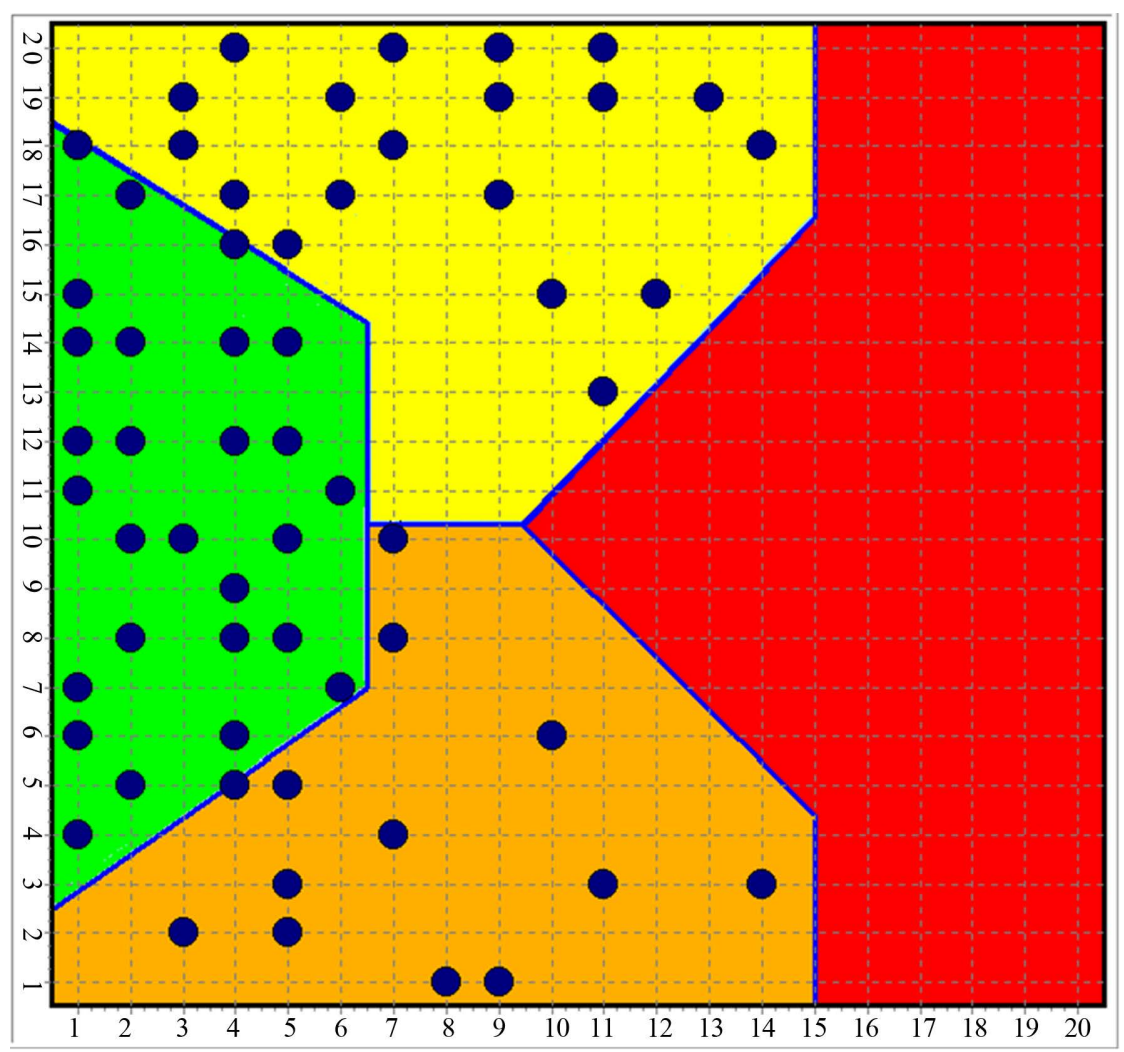

Figure 2. Distribution of normal subjects over the SOM.

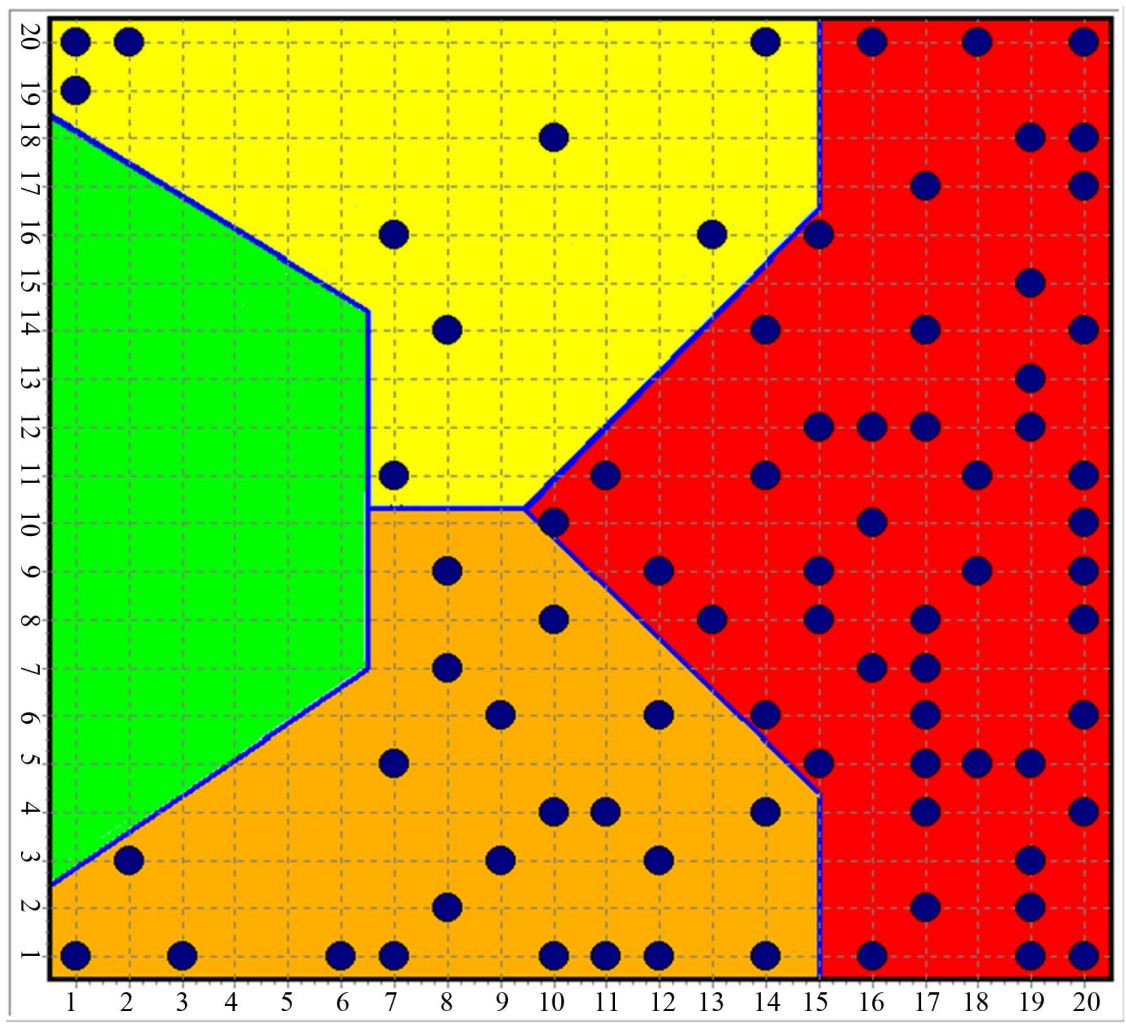

Figure 3. Distribution of subjects with mood disorders (MD and BD) over the SOM. 


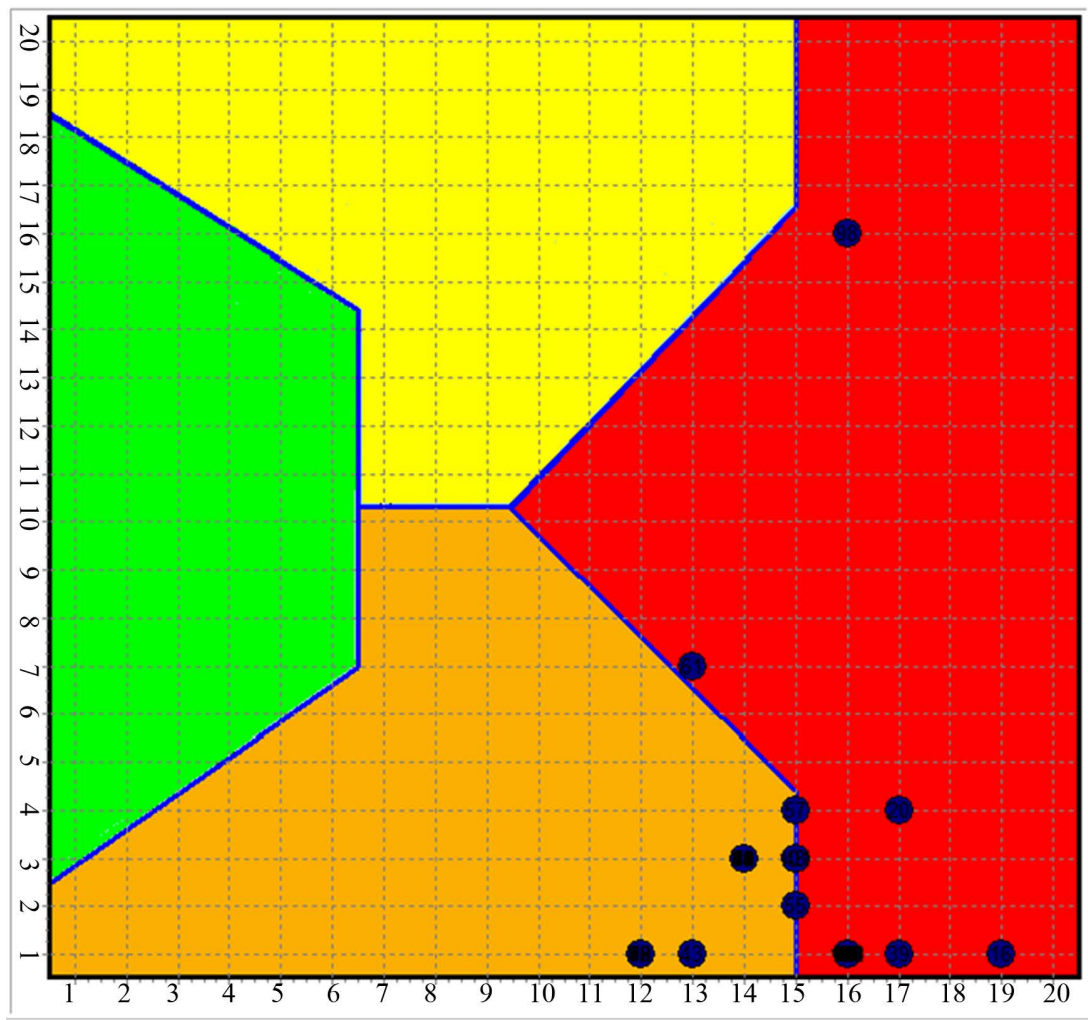

Figure 4. Distribution of the MD and BD subjects over the first SOM built.

\begin{tabular}{|c|c|c|c|c|c|c|c|c|c|c|c|c|c|c|c|c|c|c|c|c|}
\hline 20 & 2,24 & 1,17 & 1,92 & 1,89 & 1,92 & 2,04 & 2,11 & 1,85 & 1,68 & 1,59 & 1,58 & 1,56 & 1,64 & 1,60 & 1,30 & 0,99 & 0,50 & 0,02 & $-0,49$ & $-1,02$ \\
\hline 19 & 1,92 & 1,94 & 2,25 & 2,08 & 1,98 & 1,98 & 2,00 & 1,71 & 1,53 & 1,44 & 1,37 & 1,53 & 1,70 & 1,54 & 1,32 & 0,96 & 0,48 & 0,10 & 0,12 & -0.21 \\
\hline 18 & $2, x$ & 28 & 2.21 & 2.20 & 2,11 & 2.00 & 1.91 & 1.83 & 1.55 & 1.34 & 1,36 & 1.50 & 1.51 & 1.33 & 1,29 & 0.52 & 0.39 & 0,36 & 0.35 & 0.44 \\
\hline 17 & 2,36 & 2,37 & 2.27 & 2,19 & 2,22 & 2,12 & 2,04 & 1,85 & 1,77 & 1,55 & 1,39 & 1,32 & 1.31 & 1,30 & 1,23 & 0.49 & 0.39 & 0,38 & 0,43 & 0.51 \\
\hline 16 & 3,03 & 2,57 & 2,35 & 2,38 & 2,31 & 2,18 & 2,09 & 2,03 & 1,71 & 1,47 & 1,29 & 1,23 & 1,31 & 27 & 1,25 & 0.97 & 0,40 & 0,43 & 0,46 & 0.47 \\
\hline 15 & 3,21 & 3,19 & 2,59 & 2,47 & 2,53 & & 2,21 & 2,41 & 1,67 & 1,40 & 1,27 & 1,14 & 1,22 & & 1,22 & 0,72 & 0,53 & 0,47 & 0,47 & 0,15 \\
\hline 14 & 3,13 & 3,24 & 2,76 & 2,55 & 2,79 & 2,7 & 2,55 & 2,57 & 2,27 & 1,36 & 15 & 1,1 & & & 1,08 & 0,55 & 0,54 & 0,48 & 0,11 & $-0,49$ \\
\hline 13 & 2,99 & 3,05 & 2,53 & 2,44 & 2,53 & $2,4 t$ & 2,42 & 2,53 & 2,17 & 1,17 & 1,09 & & & 1,01 & 0,67 & 0.49 & 0,51 & 0,18 & $-0,01$ & -0.24 \\
\hline 12 & 2,91 & 2,83 & 2,35 & 2,28 & 2,34 & 2,18 & 2,01 & 2,06 & 1,97 & 1,63 & & & 0.79 & 0,67 & 0,60 & 0.43 & 0.49 & 0,12 & $-0,21$ & -0.27 \\
\hline 11 & 2,39 & 2,54 & 2.44 & 2,31 & 2,22 & $2,1=$ & 1,93 & 1,97 & 2,22 & 2,20 & & 1,91 & 0,79 & 0,73 & 0,63 & 0.48 & 0,31 & 0,07 & $-0,18$ & -0.38 \\
\hline 10 & 2,49 & 2,55 & 2,45 & 2,41 & 2,28 & $2,1=$ & 2,01 & 1,97 & 2,27 & 2,40 & & 1,68 & 1,07 & 0,69 & 0,55 & 0,50 & 0,35 & 0,05 & $-0,30$ & $-0,42$ \\
\hline 9 & 2,83 & 2,78 & 2,54 & 2,52 & 2,46 & 2,26 & 2,05 & 1,91 & 2,02 & 2,21 & & & 1,37 & 0,69 & 0,56 & 0,51 & 0,22 & 0,04 & $-0,24$ & $-0,40$ \\
\hline 8 & 3,28 & 3,10 & 2.78 & 2.53 & 2,57 & 2.47 & 2,23 & 2,03 & 2.01 & 2.05 & 1,91 & & 1,2 & 0,87 & 0,58 & 0.51 & 0.32 & 0,19 & $-0,41$ & -0.57 \\
\hline 7 & 3.45 & 3,33 & 2,88 & 2.69 & 2,57 & & 2,22 & 1,93 & 1.97 & 1,82 & 1,66 & 1,38 & & 0.85 & 0.63 & 0.64 & 0,38 & 0,32 & $-0,37$ & -0.51 \\
\hline 6 & 3,78 & 3,74 & 3.07 & 2.86 & & 2,59 & 2,43 & 2,06 & 2,07 & 1,54 & 1,50 & 1,40 & 1. & & 0.76 & 0.44 & 0,26 & 0,08 & $-0,36$ & -0.46 \\
\hline 5 & 4,05 & 3,80 & & & 2,93 & 2,76 & 2,54 & 2,49 & 1,99 & 1,81 & 1,83 & 1,57 & 1,12 & 0,8 & 0,75 & 0,33 & $-0,05$ & $-0,05$ & $-0,35$ & -0.54 \\
\hline 4 & 4,60 & . & 7 & 3,18 & 3,18 & 2,91 & 2,85 & 2,71 & 2,20 & 1,99 & 1,89 & 1,85 & 1,23 & 1,01 & 0,91 & 0,10 & $-0,03$ & $-0,14$ & $-0,70$ & $-0,80$ \\
\hline 3 & 12 & 4,20 & 4,19 & 3,68 & 3,45 & 3,36 & 2,90 & 2,69 & 2,42 & 2,09 & 1,93 & 1,77 & 1,51 & 1,34 & 1,18 & $-0,01$ & $-0,16$ & $-0,82$ & $-1,07$ & $-1,01$ \\
\hline 2 & 7,10 & 4,47 & 4.14 & 3.96 & 3,63 & 3.40 & 3,34 & 2,91 & 2,75 & 2,43 & 2,08 & 2.05 & 1.66 & 1.19 & 0.73 & -0.14 & -0.29 & $-1,00$ & -1.53 & -1.95 \\
\hline 1 & 8.23 & 6.58 & 4.26 & 3.98 & 3.36 & 3.06 & 3.89 & 3.07 & 2.90 & 2.50 & 2.16 & 2.34 & 1.72 & 1.03 & 0.50 & -0.03 & -0.19 & $-1,48$ & $-1,79$ & -2.64 \\
\hline & 1 & 2 & 3 & 4 & 5 & 6 & 7 & 8 & 9 & 10 & 11 & 12 & 13 & 14 & 15 & 16 & 17 & 18 & 19 & 20 \\
\hline
\end{tabular}

Figure 5. Distribution of the B2 index and overlapped the SOM clusters (dark lines). The blue line delimits the negative indexes (MD). 


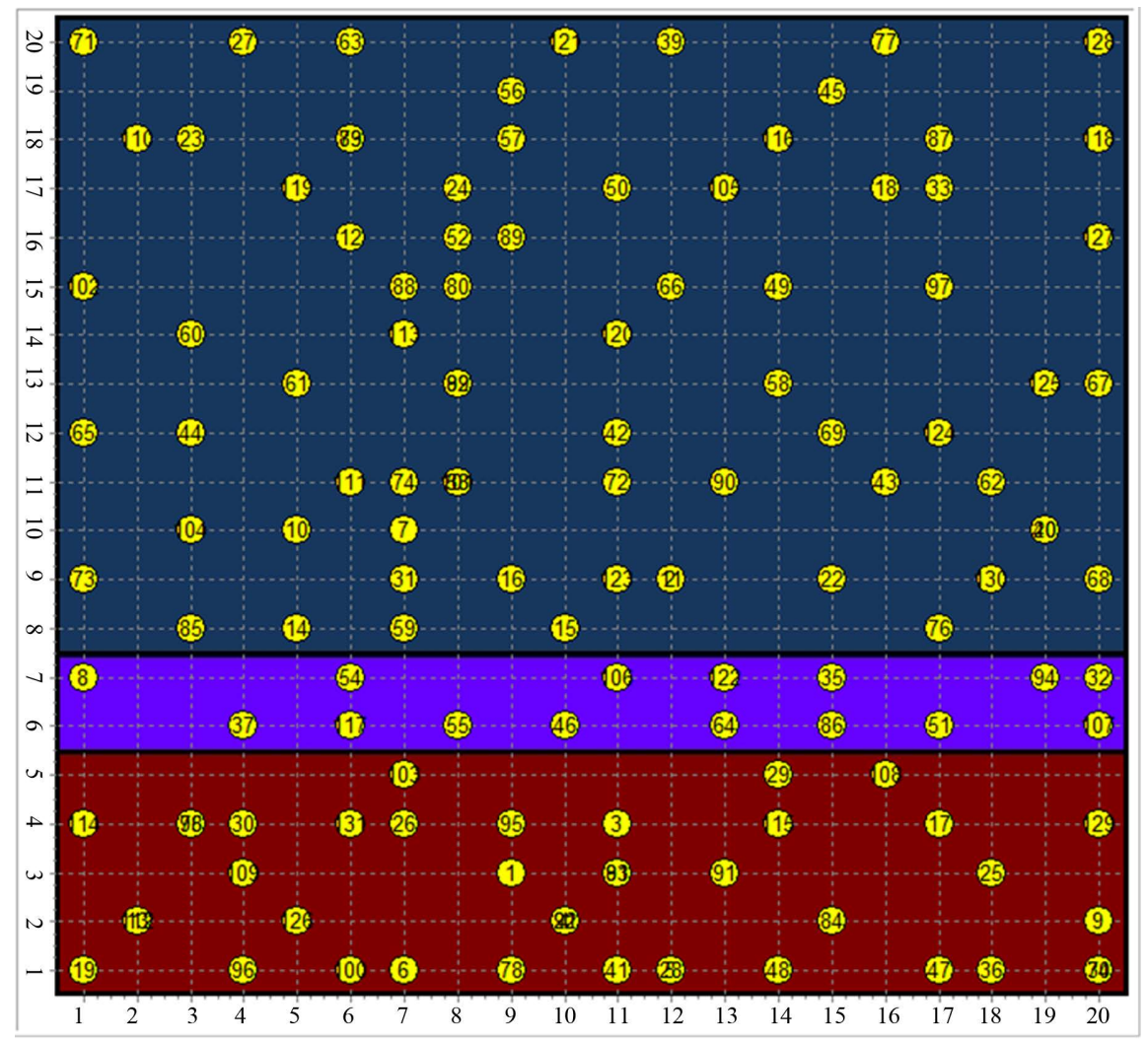

Figure 6. The new SOM recognize the MD (brown area) and the BD (blue area).

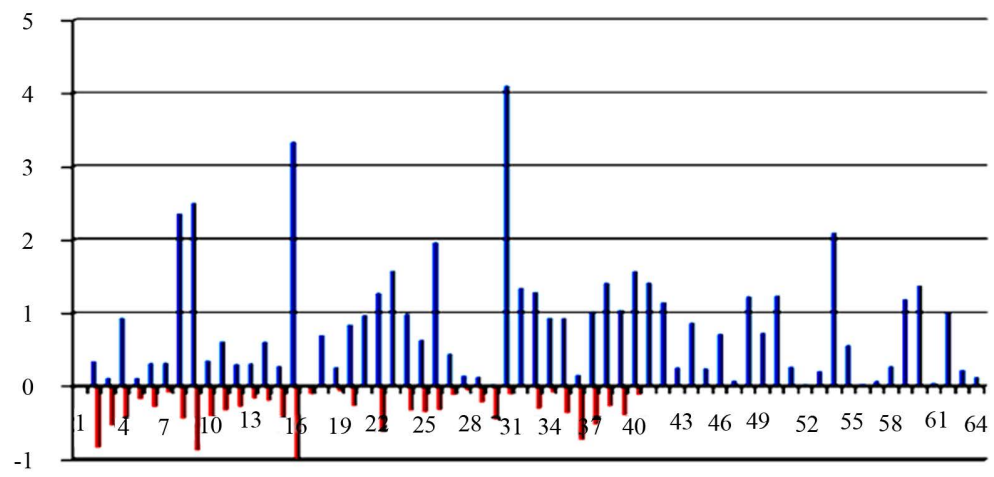

Figure 7. Histogram of the $\mathrm{B} 2$ index (blue $=\mathrm{BD}$ and red $=\mathrm{MD}$ ).

\section{Conclusive Anthropological Considerations}

The identification of three platelet fatty acids (palmitic, linoleic and arachidonic), as well as enabling identification of subjects with Mood Disorders, has introduced some hypotheses which have been recognised over time in the stability of the experimental data obtained, also with regard to the concept of capture of serotonin, on the basis of the viscosity of the membrane, so that the platelet appears an element of great similarity with the neuron, given not only its embryogenetic origin but also some molecular aspects. This evidence, together with the possibility of classifying the two principal mood disorders (Major Depression-MD and Bipolar Disorder-BD), has led to some reflections as to the molecular specificity of major depression, understood, commonly, as a phenomenon concerning only human beings and, in particular, only some of them. In this situation we are able to trace the human condition between normality, bipolar disorder and major depression, the latter being considered as a biomolecular and existential niche. 


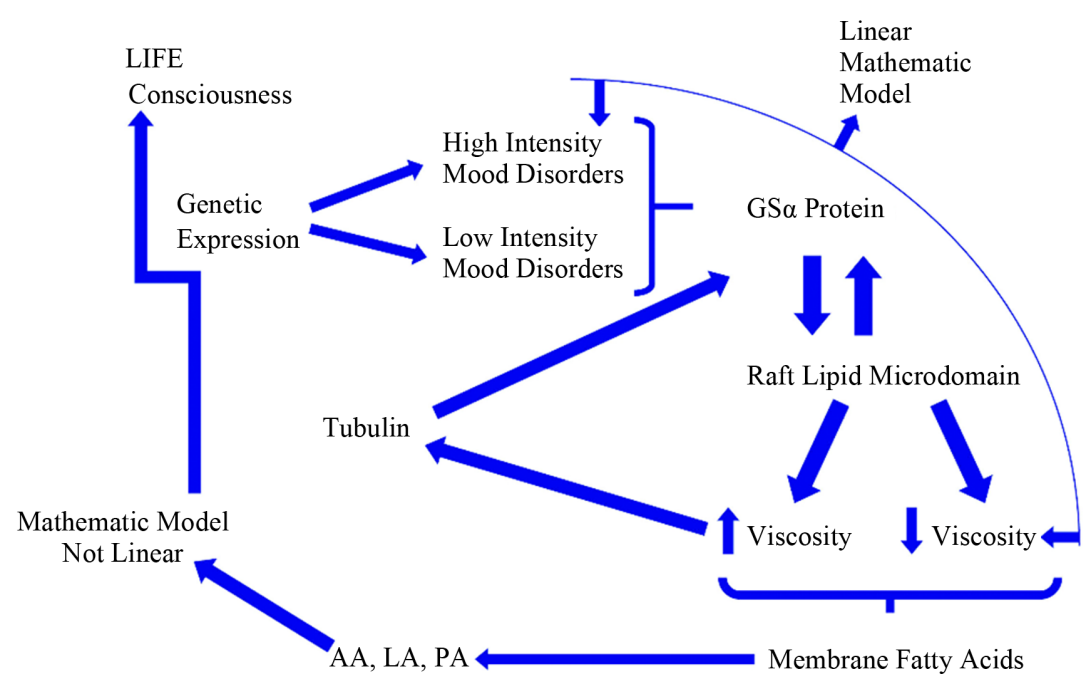

Figure 8. Molecular hypothesis (Cocchi, Hameroff, Mullis, Rasenik, Tonello, private meeting, Bologna, 2008) of consciousness that establishes a relationship between the membrane viscosity, Gs alpha protein and Tubulin (Cocchi \&Tonello, 2010; Donati et al., 2008; Hameroff \& Penrose, 1996; Hameroff, 2010).

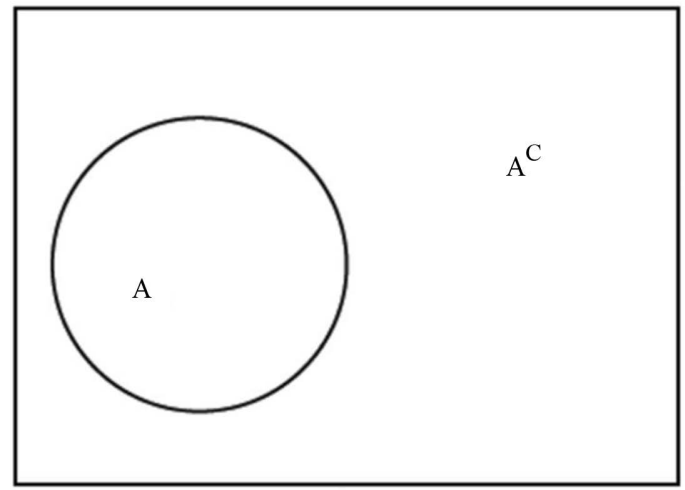

Figure 9. The U Bipartition. U is the universal representation of mankind. A is a cell whose elements are characterised by a positive B2 value. AC, as well as the completion of $\mathrm{A}$ in $\mathrm{U}$, is the cell whose elements show a negative $\mathrm{B} 2$ value (B2 is the index that establishes a relationship between the three fatty acids isolated from the SOM and the molecular weight and melting point and enables us to discriminate bipolar patients (B2 positive) from those affected by major depression (B2 negative).

From this assumption we see the emergence in summary of some stringent theoretical and anthropological focuses:

- Firstly, the distinction between first-level ontological Depression and second-level ontological Depression.

- The first kind of depression, of an existential nature, expressed by the most varied cultural traditions, is rooted in our structural contingency, which in time and in becoming recognises the mark of its own finiteness (man as an anguished and depressed "natural" animal).

- Second-level ontological Depression, on the other hand, refers to MD, understood as a molecular, 
bio-existential niche, marked cogently by serotonin and fatty acids, with its own specific “emotive tonality”.

- The centrality of the concept of situation, that is of man as a being located "here and now", starting from biological markers able to offer the diagnosis of MD and BD an extremely real substrate, to be faced on an empirical, therefore public base, to construct a DSM that is not pregnant with pseudo-phenomenology or ideology, but which looks at the dasein of consciousness in its true biomolecular flesh (Cocchi et al, 2012, 2013a).

- The continuity between biology and culture, which finds full confirmation in the phenomenon of depression, whose original (ontological) biological nature (serotonin, fatty acids) thoroughly intercepts the structural (ontological) precariousness of living that the great cultural narrations have rooted in flesh and blood (ontic) existence.

- the view of man as a synthesis of Körper and Leib: life experience is always rooted in biology, the phenomenological "losability” and "impossibility" (Minkowski, 1970) are also, and firstly, biological "losability" and "impossibility".

To remain in the distinction, often denied only in the intentions, between erklären (causal explanation) and verstehen (psychological comprehension) means ignoring the prolific acquisitions of complexity theory; above all it means remaining prisoner to the "myth of the sense", on whose basis life experiences, the phenomenological approaches, the philosophical articulations, on which an authentic interpretation of the psychopathology should depend, are hypostatised. The reification of the metaphors, the empty sentimentalism of the interior resonances, the veneration of the illness as a fruitful production of alternative worlds, the dilution of the tragedy of depression in the imaginative vis of melancholy: this is the most injurious product of pseudo-phenomenology.

Hence the need for a "gestaltic reorientation": also biology produces sense, indeed it is the original meaning on which to graft other forms of meaning, of which philosophy is undoubtedly a strong interlocutor, but alongside other forms of knowledge (biochemistry, quantum physics, biomathematics, anthropology, sociology...), as an overall, heuristic synthesis, expressive of an autonomous, therefore "adult”, approach to psychopathology (Cocchi et al., 2013a).

Lastly, it is necessary that the scientific community and the world of the clinical profession commit themselves increasingly so that psychiatry and psychology can constitute themselves as heuristic bio-analytical-existential knowledge, where the diagnosis is not placed under the Heideggerian "yoke of the idea” (classificatory ideology and diagnostic imperialism), but refers to convincing biological markers. In this context, comparison with the neurosciences appears inescapable, particularly in their quantistic standpoint (Pothos \& Busemeyer, 2013; Woolf et al., 2010; Pylkkänen, 2010; Zizzi \& Pregnolato, 2012; Mender, 2013; Cocchi et al., 2013b), with all the implications, also of an ethical nature, that this involves (Garland, 2004; Furman, Downey, \& Jackson, 2004; Gazzaniga, 2005; Glannon, 2006; Illes, 2006; Levy, 2007; Illes \& Sahakian, 2011; Benedikter \& Giordano, 2012; Giordano, 2012; Kohls et al., 2013; Monti, 2013).

In other words, to start from biology to move towards increasingly complex systems, able to integrate biochemical expressions, living and irreducible existential experiences, social and cultural contexts. Depression therefore needs to be inscribed within a horizon of unmythicised, polyvocal meaning where the biological, physiological, clinical, existential, psycho-social and anthropological aspects are set as objective a hermeneutic framework as possible.

This is all the more so at a time like the present, when a person is often appraised only on the basis of successes achieved, of objects flaunted, of products voraciously consumed, in the instant, of his social visibility, of relentless efficacy, of perfect adaptation of the "thinkable to the possible": all contexts where the genetic and biological psychopathologies of mood are disproportionately amplified (Bauman, 2007; Bertman, 1998; Eriksen, 2001; Gabrielli, 2012).

\section{References}

Augé, M., \& Herzlich, C. (1984). Le sens du mal. Anthropologie, histoire, sociologie de la maladie, Éditions des archives contemporaines, Paris.

Baker, L. (2000). Persons and Bodies. A Constitution View. Cambridge: Cambridge University Press. http://dx.doi.org/10.1017/CBO9781139173124

Baker, L. (2002). The Ontological Status of Persons. Philosophy and Phenomenological Research, 65.

Bateson, G., \& Bateson, M. C. (1987). Angels Fear: Towards an Epistemology of the Sacred. New York: Macmillan. 
Bauman, Z. (2007). Consuming Life. Oxford: Polity Press.

Benedikter, R., \& Giordano J. (2012). Neurotechnology: New Frontiers for European Policy. Pan Euro Network Sci Tech, 3, 204-207.

Bertman, S. (1998). Hyperculture. The Human Cost of Speed, Praeger, Westport (CO)-London.

Binswanger, L. (1963). Being in the World: Selected Papers of Ludwig Binswanger. New York: Basic Books.

Bowden, C. L. (2001). Strategies to Reduce Misdiagnosis of Bipolar Depression. Psychiatric Services, 52, 51-55. http://dx.doi.org/10.1176/appi.ps.52.1.51

Cocchi, M., Gabrielli, F., Tonello, L., \& Castaldo, A. (2013a). Music, Brain, Consciousness. Lugano: Ludes University Press.

Cocchi, M., Gabrielli, F., Pessa, E., Pregnolato, M., Tonello, L., \& Zizzi, P. (2012c). Major Depression and Bipolar Disorder: The Concept of Symmetry Breaking. NeuroQuantology, 10, 676-687. http://dx.doi.org/10.14704/nq.2012.10.4.577

Cocchi, M., Gabrielli, F., Tonello, L., Delogu, M., Beghelli, V., Mattioli, M., \& Accorsi, P. A. (2013b). Molecular Contiguity between Human and Animal Consciousness through Evolution: Some Considerations. Journal of Phylogenetics \& Evolutionary Biology, 1, 4, 2-8, http://dx.doi.org/10.4172/2329-9002.1000119.

Cocchi, M., \& Tonello, L. (2010). Bio-Molecular Considerations in Major Depression and Ischemic Cardiovascular Disease. Central Nervous System Agents in Medicinal Chemistry, 10, 97-107. http://dx.doi.org/10.2174/187152410791196378

Cocchi, M., Tonello, L., \& Gabrielli, F. (2012). Considerations on Blood Platelets: A Neuron’s Mirror for Mood Disorders? Open Journal of Blood Diseases, 2, 22-29. http://dx.doi.org/10.4236/ojbd.2012.22005

Cocchi, M., Tonello, L., \& Gabrielli, F. (2012b). Molecular Uniqueness of Major Depression: Biological Remarks and Theoretical Implications. Journal of Consciousness Exploration \& Research, 3, 380-391.

Cocchi, M., Tonello, L., \& Rasenick, M. M. (2010b). Human Depression: A New Approach in Quantitative Psychiatry. Annals of General Psychiatry, 9, 25. http://dx.doi.org/10.1186/1744-859X-9-25

Cocchi, M., Tonello, L., Tsaluchidu, S., \& Puri, B. K. (2008). The Use of Artificial Neural Networks to Study Fatty Acids in Neuropsychiatric Disorders. BMC Psychiatry, 8, S3. http://dx.doi.org/10.1186/1471-244X-8-S1-S3

Donati, R. J., Dwivedi, Y., Roberts, R. C., Conley, R. R., Pandey, G. N., \& Rasenick, M. M. (2008). Postmortem Brain Tissue of Depressed Suicides Reveals Increased Gs Localization in Lipid Raft Domains Where It Is Less Likely to Activate Adenylyl Cyclase. The Journal of Neuroscience, 28, 3042-3050.

http://dx.doi.org/10.1523/JNEUROSCI.5713-07.2008

Deleuze, G., \& Guattari (2004). Anti-Oedipus, Continuum, London and New York, Vol. 1 of Capitalism and Schizophrenia, 2 vols. $1972-1980$.

Eriksen, T. H. (2001).Tyranny of the Moment: Fast and Slow Time in the Information Age, Pluto Press, London-Sterling.

Foucault, M. (1965). Madness and Civilization: A History of Insanity in the Age of Reason Tavistock. London.

Foucault, M. (1994). The Birth of the Clinic: An Archaeology of Medical Perception. New York: Vintage.

Foucault, M. (2004). Abnormal: Lectures at the Collège de France, 1974-1975. New York: Picador.

Foucault, M. (2008). Psychiatric Power: Lectures at the Collège de France, 1973-1974. New York: Picador.

Furman, R., Downey, E. P., \& Jackson, R. L. (2004). Exploring the Ethics of Treatments for Depression: The Ethics of Care Perspective. Smith College Studies in Social Work, 74, 525-538. http://dx.doi.org/10.1080/00377310409517733

Gabrielli, F. (2012). Philosophy and Psychiatry. The Violated Body in the Era of the Invisible Man. NeuroQuantology, 10, 19-20.

Garland, B. (2004). Neuroscience and the Law. New York: Dana Press.

Gazzaniga, M. (2005). The Ethical Brain. New York: Dana Press.

Giordano, J. (2012). Neuroimaging in Psychiatry: Approaching the Puzzle as a Piece of the Bigger Picture(s). AJOB-Neuroscience, 3, 54-56. http://dx.doi.org/10.1080/21507740.2012.721469

Glannon, W. (2006). Bioethics on the Brain. New York: Oxford University Press. http://dx.doi.org/10.1093/acprof:oso/9780195307788.001.0001

Goffman, E. (1961). Asylums: Essays on the Social Situation of Mental Patients and Other Inmates. New York: Anchor Books.

Good, J. B. (1994). Medicine, Rationality and Experience: An Anthropological Perspective. Cambridge: Cambridge University Press. 
Hameroff, S. R., \& Penrose, R. (1996). Orchestrated Reduction of Quantum Coherence in Brain Microtubules: A Model for Consciousness. In S. R. Hameroff, A. Kaszniak and A. C. Scott (Eds.), Toward a Science of Consciousness-The First Tucson Discussions and Debates (pp. 507-540). Cambridge, MA: MIT Press.

Hameroff, S. R. (2010). The “Conscious Pilot”-Dendritic Synchrony Moves through the Brain to Mediate Consciousness. Journal of Biological Physics, 36, 71-93. http://dx.doi.org/10.1007/s10867-009-9148-X

Husserl, E. (1911). Philosophie als Strenge Wissenschaft. Logos, I, 1910-1911.

Husserl, E. (1977). Cartesian Meditations: An Introduction to Phenomenology. Dordrecht: Kluwer Academic Publishers.

Illes, J., \& Sahakian, B. J. (Eds.) (2011). Oxford HandDook of Neuroethics. Oxford: Oxford University Press. http://dx.doi.org/10.1093/oxfordhb/9780199570706.001.0001

Jaspers, K. (1963). General Psychopathology. Chicago, IL: University of Chicago Press.

Kohls, N. B., DuRousseau, D., Plischke, H., \& Giordano, J. (2013). Brain-Computer Interfacing (BCI): Potential Use and Ethico-Legal and Social Issues-Toward a Stance of Preparation and Steps Forward. Human Computer Interfacing International, 10, Online.

Kohonen, T. (1982). Self-Organized Formation of Topologically Correct Feature Maps. Biological Cybernetics, $43,59-69$. http://dx.doi.org/10.1007/BF00337288

Kohonen, T. (2001). Self-Organizing Maps (3rd ed.). Berlin: Springer. http://dx.doi.org/10.1007/978-3-642-56927-2

Kohonen, T., Kaski, S., Somervuo, P., Lagus, K., Oja, M., \& Paatero, V. (1998). Self-Organizing Map. Neurocomputing, 21, 113-122.

Laín Entralgo, P. (1970). The Therapy of the Word in Classical Antiquity. New Haven, CT: Yale University Press.

Levy, N. (2007). Neuroethics. Challenges for the 21st Century. Cambridge: Cambridge University Press. http://dx.doi.org/10.1017/CBO9780511811890

Maruyama, M. (1976). Toward Cultural Symbiosis, Jantsch e Waddington (ed.), Evolution and Consciousness. Reading, MA: Addison Wesley.

Mann, Th. (1996). The Magic Mountain. New York: Vintage Books.

Mender, D. (2013). The Cunning of the Observable: Generalized Fourier Duality, the Hard Problem, and Natural Kinds of Psychopathology. Quantum Biosystems, 5, 43-54.

Merleau-Ponty, M. (1964). The Primacy of Perception: And Other Essays on Phenomenological Psychology, the Philosophy of Art, History and Politics. Evanston: Northwestern University Press.

Minkowski, E. (1970). Lived Time: Phenomenological and Psychopathological Studies. Evanston: Northwestern University Press.

Monti, M. M. (2013). Ethics, Neuroimaging and Disorders of Consciousness: What Is the Question? AJOB Neuroscience, 4 , 1-2. http://dx.doi.org/10.1080/21507740.2013.836337

Morin, E. (1973). Le Paradigme perdu: La Nature Humaine. Paris: Seuil.

Morin, E. (1984). Epistémologie de la Complexité. Revue de la Recerche Juridique et de Droit Prospectif, 1, 47-79.

Morin, E. (2008). On Complexity. Creskill, NJ: Ed Hampton Press, Inc.

Pothos, E. M., \& Busemeyer, J. R. ( 2013). Can Quantum Probability Provide a New Direction for Cognitive Modeling? Behavioral and Brain Sciences, 36, 255-327. http://dx.doi.org/10.1017/S0140525X12001525

Pylkkänen, P. (2010). Implications of Bohmian Quantum Ontology for Psychopathology. NeuroQuantology, 8, 13-28.

Woolf, N., Craddock, T. J. A., Friesen, D. E., \& Tuszynski, J. A. (2010). Impaired Neuroplasticity and Possible Quantum Processing Derailment in Microtubules. NeuroQuantology, 1, 13-28. http://dx.doi.org/10.14704/nq.2010.8.1.265

Young, A. (1982). The Anthropologies of Illness and Sickness. Annual Review of Anthropology, 11, 257-285. http://dx.doi.org/10.1146/annurev.an.11.100182.001353

Zizzi, P., \& Pregnolato, M. (2012). Quantum Logic of the Unconscious and Schizophrenia Paradigms Quantum Logic of the Unconscious and Schizophrenia. NeuroQuantology, 10, 566-579. http://dx.doi.org/10.14704/nq.2012.10.3.550 